\title{
APLIKASI KEAMANAN DATA MENGGUNAKAN METODE MMB
}

\section{DAN LSB}

\author{
Fajar Dewandaru', Cahya Rahmad ${ }^{2}$ \\ ${ }^{1}$ Teknik Informatika, Teknologi Informasi,Politeknik Negeri Malang \\ ${ }^{1}$ fajar.dewandaru@gmail.com, ${ }^{2}$ cahya.rahmad@yahoo.com
}

\begin{abstract}
Abstrak
Teknologi informasi dapat membantu pekerjaan manusia khususnya yang berhubungan dengan pemrosesan ataupun pendistribusian informasi. Namun, seiring dengan berkembangnya hal tersebut berkembang pula pelangaran atau penyalahgunaan dalam keamanan pesan yang dikirim seperti dengan cara merusak, menyadap, merubah pesan tersebut untuk kepentingan pribadi. Untuk itu diperlukan suatu sistem keamanan yang dapat melindungi suatu informasi menggunakan ilmu untuk menyembunyikan atau mengamankan suatu pesan atau informasi ke dalam pesan lain yaitu dengan teknik steganografi serta proses penyandian suatu informasi atau data rahasia yang berbentuk teks menjadi bentuk lain yang tidak dapat dipahami yaitu teknik kriptografi. Dengan penggabungan dari kedua metode ini maka pesan atau informasi yang disembunyikan akan sulit untuk dipecahkan atau dibobol, karena memiliki dua tingkat keamanan.
\end{abstract}

Kata kunci: steganografi, kriptografi, MMB, LSB.

\section{Pendahuluan}

Pada era modern saat ini, teknologi informasi dan komunikasi merupakan suatu kebutuhan manusia yang tidak dapat terpisahkan lagi dalam melakukan setiap kegiatan di bidang pendidikan maupun dunia kerja. Teknologi informasi dapat membantu pekerjaan manusia khususnya yang berhubungan dengan pemrosesan ataupun pendistribusian informasi. Seiring dengan berkembangnya teknologi informasi akan mempermudah manusia dalam berkirim pesan maupun menerima pesan. Pesan yang disampaikan ada kalanya berupa pesan yang bersifat rahasia sehingga tidak semua pihak dapat melihat pesan tersebut. Namun, seiring dengan berkembangnya hal tersebut berkembang pula pelangaran atau penyalahgunaan dalam keamanan pesan yang dikirim seperti dengan cara merusak, menyadap, merubah pesan tersebut untuk kepentingan pribadi. Kegiatan tersebut membuat informasi atau pesan yang bersifat rahasia dapat dilihat oleh orang yang tidak bertanggung jawab. Oleh karena itu, masalah keamanan informasi menjadi hal yang sangat penting dalam suatu sistem informasi untuk keamanan bersama maupun keamanan pribadi. Untuk itu diperlukan suatu sistem keamanan yang dapat melindungi suatu informasi.

Menurut Cahyadi (2012), steganografi merupakan ilmu yang mempelajari, meneliti, dan mengembangkan seni menyembunyikan sesuatu informasi. Metode steganografi yang sederhana dan mudah untuk diimplementasikan adalah metode LSB (Least Significant Bit). LSB adalah metode yang menggunakan algoritma sederhana yang menukar bit paling kecil ke dalam beberapa byte media penyembunyian secara berurutan. Kelemahan dari metode LSB adalah pesan rahasia yang telah disisipkan dapat dengan mudah diambil kembali dengan menggunakan metode LSB jika diketahui oleh orang lain. Untuk menutupi kekurangan dari metode tersebut dilakukan proses penyandian suatu informasi atau data rahasia yang berbentuk teks menjadi bentuk lain yang tidak dapat dipahami sebelum disisipkan menggunakan metode LSB, teknik ini disebut teknik kriptografi.

Kriptografi merupakan suatu ilmu yang mempelajari tentang teknik atau cara merahasiakan dan mengembalikan ke bentuk semula suatu pesan dengan cara unik yang berhubungan dengan aspek keamanan informasi. Metode kriptografi yang dapat digunakan untuk mengamankan data sangat beragam, salah satunya adalah metode MMB (Modular Multiplication-based Block Cipher). MMB adalah algoritma block cipher pengembangan dari metode kriptografi IDEA yang juga berbasis block cipher yang sebelumnya sering digunakan dalam mengenkripsi dan mendekripsi suatu pesan atau informasi.

Untuk meningkatkan kemanan pesan dan informasi yang dirahasiakan serta pengimplementasian metode tersebut dalam aplikasi maka penulis membuat "Aplikasi Keamanan Data Menggunakan Teknik Kriptografi dan Steganografi Dengan Metode MMB dan LSB”, dengan cara pesan yang akan disisipkan menggunakan metode LSB terlebih dahulu dienkripsi menggunakan metode MMB. 


\section{Steganografi}

Steganografi merupakan suatu ilmu atau seni dalam menyembunyikan informasi dengan memasukkan informasi rahasia kedalam pesan lain. Dengan demikian keberadaan informasi tersebut tidak diketahui oleh orang lain. Menyembunyikan keberadaan pesan dan dapat dianggap sebagai pelengkap dari kriptografi yang bertujuan untuk menyembunyikan isi pesan adalah tujuan utama dari steganografi (Cahyadi, 2010). Dalam steganografi pesan disembunyikan sedemikian rupa sehingga pihak lain tidak dapat mengetahui adanya pesan rahasia. Pesan tersebut hanya disembunyikan ke dalam suatu media berupa gambar, teks, musik, atau media digital lainnya dan terlihat seperti pesan biasa.

\section{Kriptografi}

Kriptografi adalah ilmu yang mempelajari teknik - teknik matematika yang berhubungan dengan aspek-aspek pada keamanan informasi misalnya kerahasiaan, integritas data, otentikasi pengirim / penerima data, dan otentikasi data. Teknik ini digunakan untuk mengubah data ke dalam kodekode tertentu, dengan tujuan informasi yang disimpan atau ditransmisikan melalui jaringan yang tidak aman tidak dapat dibaca oleh siapa pun kecuali orang-orang yang berhak.

Terdapat dua proses penting di dalam kriptografi yang berperan dalam merahasiakan suatu informasi yakni enkripsi (encryption) dan dekripsi (decryption). Enkripsi adalah transformasi data (plaintext) ke dalam bentuk yang hampir tidak dapat dibaca (ciphertext) tanpa pengetahuan yang cukup. Sedangkan dekripsi adalah kebalikan dari enkripsi, yakni transformasi dari data yang telah dienkripsi (ciphertext) kembali ke bentuk semula (plaintext). Proses enkripsi dan dekripsi pada umumnya membutuhkan penggunaan sejumlah informasi yang rahasia, yang sering disebut kunci (key) (Latief, 2010:1).

\section{Metode MMB}

Kriptografi metode MMB menggunakan plaintext 128 bit dan algoritma iteratif yang terdiri dari langkah-langkah linier (seperti XOR dan aplikasi kunci) serta aplikasi paralel dari empat substitusi non linier besar yang dapat dibalik. Substitusi ini ditentukan oleh sebuah operasi perkalian modulo $2^{32}$ - 1 dengan faktor konstan, yang memiliki tingkat sekuritas lebih tinggi. MMB menggunakan 32 bit sub block text (x0, x1, x2, x3) dan 32 bit sub block kunci (k0, k1, k2, k3). Hal ini membuat algoritma tersebut sangat cocok diimplementasikan pada prosesor $32 \mathrm{bit}$. Sebuah fungsi non linier, f, diterapkan enam kali bersama dengan fungsi XOR (Latief, 2010: 4). Metode MMB menggunakan kunci sepanjang 128 bit. Proses pembentukan kunci pada metode MMB ini sangat sederhana. Kunci yang di-input hanya dibagi menjadi 4 buah sub block kunci dengan panjang masing-masing 32 bit. Proses pembentukan kunci pada metode MMB ini dapat dilihat pada bagan berikut ini:

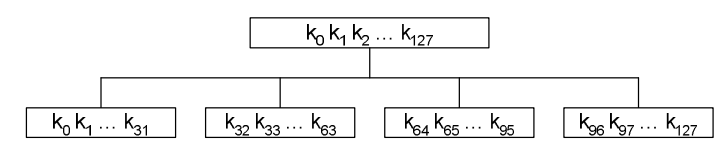

Gambar 2.5 Proses Pembentukan Kunci pada

Metode MMB (Sumber: Latief, 2010: 4)

Metode MMB menggunakan kunci dan plaintext dengan panjang 16 karakter atau 128 bit. Proses enkripsi metode MMB digambarkan dengan diagram alur sebagai berikut:

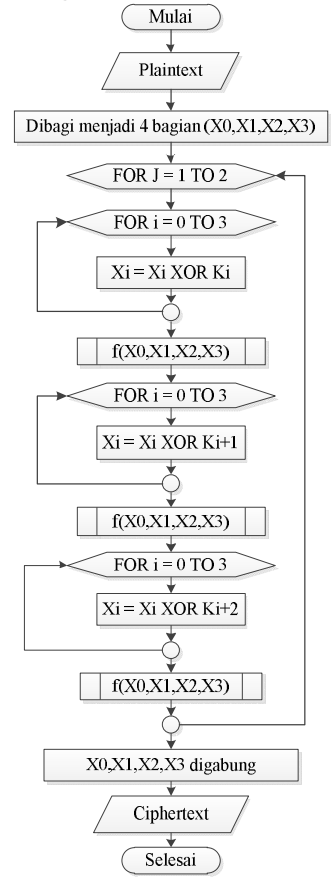

Gambar 3.5 Proses Enkripsi MMB (Sumber: Latief, 2010: 4)

Fungsi $f$ yang digunakan dijelaskan pada diagram alur sebagai berikut:

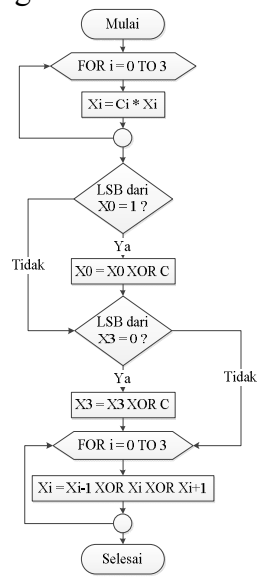

Gambar 3.6 Fungsi f Enkripsi (Sumber: Latief, 2010: 5)

Operasi perkalian yang digunakan merupakan operasi modulo $2^{32}-1$. Konstanta yang digunakan dirincikan sebagai berikut:

- $\mathrm{C}=(2 \mathrm{AAAAAAA})_{16}$

$-\mathrm{C}_{0}=(025 \mathrm{~F} 1 \mathrm{CDB})_{16}$

$-\mathrm{C}_{1}=2 * \mathrm{C}_{0}$ 


$$
\text { - } \mathrm{C}_{2}=2^{3} * \mathrm{C}_{0}
$$$$
\text { - } \mathrm{C}_{3}=2^{7} * \mathrm{C}_{0}
$$

\section{Metode LSB}

Metode LSB (Least Significant Bit) bekerja dengan cara mengganti bit terakhir dari masingmasing piksel dengan pesan yang akan disisipkan. LSB mempunyai kelebihan yakni ukuran gambar tidak akan berubah. Sedangkan kekurangannya adalah pesan/ data yang akan disisipkan terbatas, sesuai dengan ukuran citra (Krisnawati, 2008: 40). Bit yang cocok untuk diganti adalah bit LSB, sebab perubahan tersebut hanya mengubah nilai byte satu lebih tinggi atau satu lebih rendah dari nilai sebelumnya.

Sebagai contoh, Pada proses encode atau penyisipan untuk menyisipkan 1 karakter dibutuhkan 3 pixel gambar, contohnya dapat digambarkan sebagai berikut:

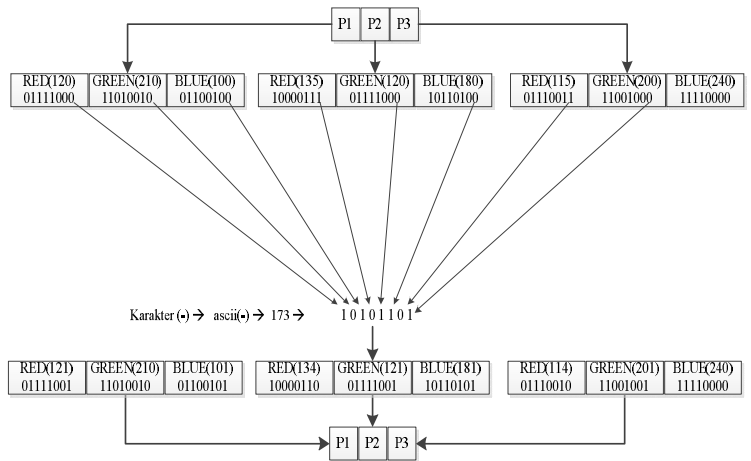

Gambar 4.1 Encode Metode LSB (Sumber: Implementasi)

\section{Kombinasi Metode MMB dan LSB}

Proses enkripsi dan encode membutuhkan pesan (plaintext) dan gambar yang akan disisipi (cover-image) yang selanjutnya plaintext digunakan dalam proses algoritma MMB dan menghasilkan pesan yang telah dienkripsi (ciphertext). Selanjutnya ciphertext disisipkan ke dalam gambar (cover-image) menggunakan algoritma LSB dan hasilnya adalah gambar yang telah disisipi (stego-image). Proses enkripsi dan encode tersebut dapat lebih dijelaskan secara rinci dengan diagram alur di dalam Gambar 3.10 .

Dalam proses tersebut dibutuhkan masukan pesan (plaintext), kunci yang telah menjadi 4 bagian sama besar, dan gambar (cover-image) selanjutnya dilakukan penghitungan panjang dari plaintext, apabila panjang plaintext lebih besar dari 16 maka hanya diambil 16 karakter sebagai plaintext, apabila plaintext lebih kecil dari 16 maka ditambahkan karakter spasi sampai jumlah plaintext sama dengan 16, jika plaintext sama dengan 16 proses selanjutnya yaitu mengkonversi plaintext ke bentuk desimal, lalu konversi desimal tersebut ke biner, biner plaintext tersebut selanjutnya dibagi menjadi 4 bagian sama besar, selanjutnya dilakukan proses algoritma metode MMB yaitu operasi XOR antara plaintext dan kunci, fungsi f, mengikuti alur tersebut hingga menggabungkan kembali pesan dan menghasilkan pesan yang telah dienkripsi (ciphertext), selanjutnya mengambil pixel gambar, mengkonversi ciphertext ke bentuk biner, dan menghitung kapasitas tampung gambar (cover-image), jika memenuhi kebutuhan maka dilanjutkan dengan mengkonversi pixel gambar ke desimal dan konversi kembali ke bentuk biner, lalu menyisipkan biner ciphertext ke bit terakhir dari biner pixel, konversi biner pixel ke desimal dan konversi kembali menjadi pixel gambar, setelah itu akan menghasilkan keluaran gambar yang telah disisipi (stego-image).

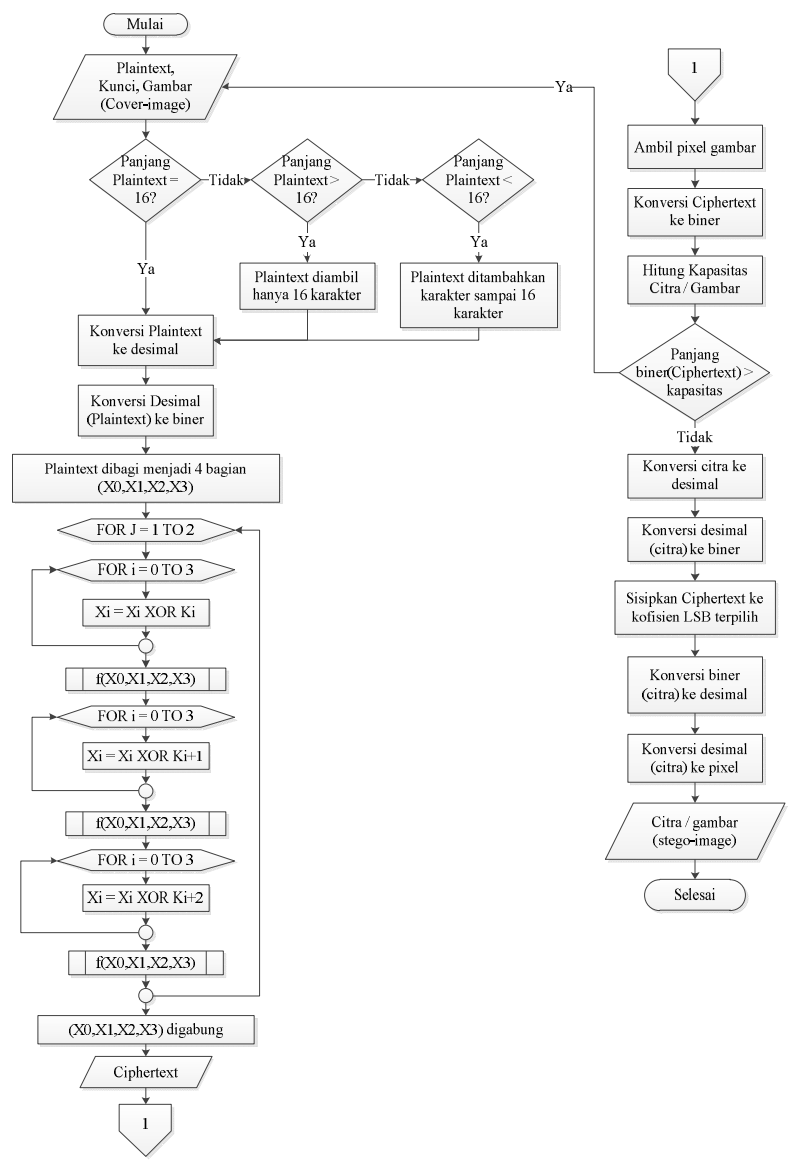

Gambar 3.10 Proses Enkripsi Kombinasi dari Metode MMB dan LSB (Sumber: Perancangan)

Setelah proses enkripsi dan encode dilakukan, untuk mengambil kembali pesan yang disembunyikan dilakukan proses dekripsi dan ekstraksi/ decode dengan alur di dalam Gambar 3.11.

Dari alur tersebut dibutuhkan masukan gambar (stego-image) dan kunci, mengambil pixel gambar (stego-image), konversi pixel ke desimal, konversi kembali ke bentuk biner, selanjutnya mengekstraksi ciphertext dari gambar dengan algoritma LSB dengan mengambil bit terakhir dari biner gambar (stego-image), konversi ciphertext ke bentuk desimal, konversi kembali ke bentuk biner, biner ciphertext dibagi menjadi 4 bagian yang sama besar, kemudian melakukan dekripsi menggunakan 
algoritma MMB dengan melakukan fungsi f dekripsi, operasi XOR antara ciphertext dan kunci, lalu melakukan proses mengikuti alur tersebut hingga mengabungkan kembali pesan, konversi pesan tersebut ke desimal, dan menghasilkan plaintext.
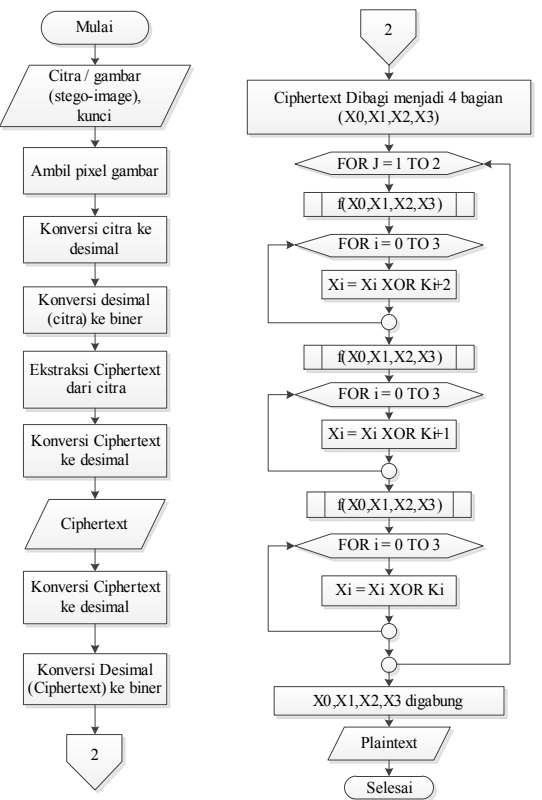

Gambar 3.11 Proses Deskripsi Kombinasi dari Metode MMB dan LSB (Sumber: Perancangan)

\section{Hasil Pengujian}

Dari uji coba yang telah dilakukan terhadap 3 file teks dengan besar ukuran file 16 bytes, dalam melakukan proses enkripsi hasil yang didapatkan adalah perubahan pesan ke bentuk yang tidak dapat diartikan atau ciphertext sebagai berikut:

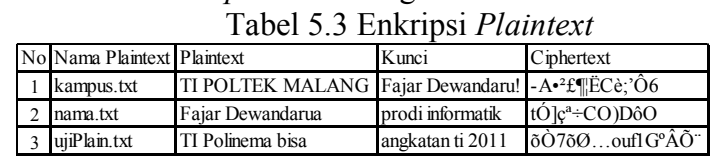

Dari data tersebut, ciphertext yang dihasilkan disisipkan ke dalam gambar yang telah dipilih dengan rincian sebagai berikut:

Tabel 5.4 Hasil Enkripsi dan Penyisipan atau

\begin{tabular}{|c|c|c|c|c|c|c|}
\hline \multirow{2}{*}{ No } & \multicolumn{4}{|c|}{ Sebelum Proses Enkripsi } & \multicolumn{2}{|c|}{ Setelah Proses Enkripsi } \\
\hline & Cover-image & Ukuran Cover & Dimensi & Plaintext & Ukuran Stego & Waktu Proses \\
\hline & \multirow{3}{*}{ airTerjunl.bmp } & \multirow{3}{*}{ 1351.254 Bytes } & \multirow{3}{*}{$750 \times 600$} & kampus.txt & 1351.254 Bytes & $0: 0: 23: 307$ \\
\hline & & & & nama.txt & 1351.254 Bytes & $0: 0: 23: 370$ \\
\hline & & & & ujiPlain.txt & 1351.254 Bytes & $0: 0: 23: 137$ \\
\hline \multirow{3}{*}{2} & \multirow{3}{*}{ boy2.bmp } & \multirow{3}{*}{810.294 Bytes } & \multirow{3}{*}{$640 \times 422$} & kampus.txt & 810.294 Bytes & $0: 0: 21: 255$ \\
\hline & & & & nama.txt & 810.294 Bytes & $0: 0: 21: 590$ \\
\hline & & & & ujiPlain.txt & 810.294 Bytes & $0: 0: 21: 459$ \\
\hline \multirow{3}{*}{3} & \multirow{3}{*}{ flying3.bmp } & \multirow{3}{*}{439.542 Bytes } & \multirow{3}{*}{$448 \times 327$} & kampus.txt & 439.542 Bytes & $0: 0: 20: 272$ \\
\hline & & & & nama.txt & 439.542 Bytes & $0: 0: 20: 323$ \\
\hline & & & & ujiPlain.txt & 439.542 Bytes & $0: 0: 20: 176$ \\
\hline \multirow{3}{*}{4} & \multirow{3}{*}{ pantail.bmp } & \multirow{3}{*}{1200.054 Bytes } & \multirow{3}{*}{$800 \times 500$} & kampus.txt & 1200.054 Bytes & $0: 0: 22: 727$ \\
\hline & & & & nama.txt & 1200.054 Bytes & $0: 0: 22: 901$ \\
\hline & & & & ujiPlain.txt & 1200.054 Bytes & $0: 0: 22: 937$ \\
\hline \multirow{3}{*}{5} & \multirow{3}{*}{ merpati2.bmp } & \multirow{3}{*}{ 833.334 Bytes } & \multirow{3}{*}{$640 \times 434$} & kampus.txt & 833.334 Bytes & $0: 0: 21: 569$ \\
\hline & & & & nama.txt & 833.334 Bytes & $0: 0: 21: 614$ \\
\hline & & & & ujiPlain.txt & 833.334 Bytes & $0: 0: 21: 599$ \\
\hline \multirow{3}{*}{6} & \multirow{3}{*}{ ngun3.bmp } & \multirow{3}{*}{451.638 Bytes } & \multirow{3}{*}{$448 \times 336$} & kampus.txt & 451.638 Bytes & $0: 0: 20: 215$ \\
\hline & & & & nama.txt & 451.638 Bytes & $0: 0: 20: 409$ \\
\hline & & & & $\overline{\text { ujiPlain.txt }}$ & 451.638 Bytes & $0: 0: 20: 17$ \\
\hline
\end{tabular}

Perbandingan gambar sebelum proses enkripsi dan penyisipan (cover-image) dengan gambar setelah proses enkripsi dan penyisipan (stego-image) sebagai berikut:

Tabel 5.7 Perbandingan Cover-image dan Stegano-

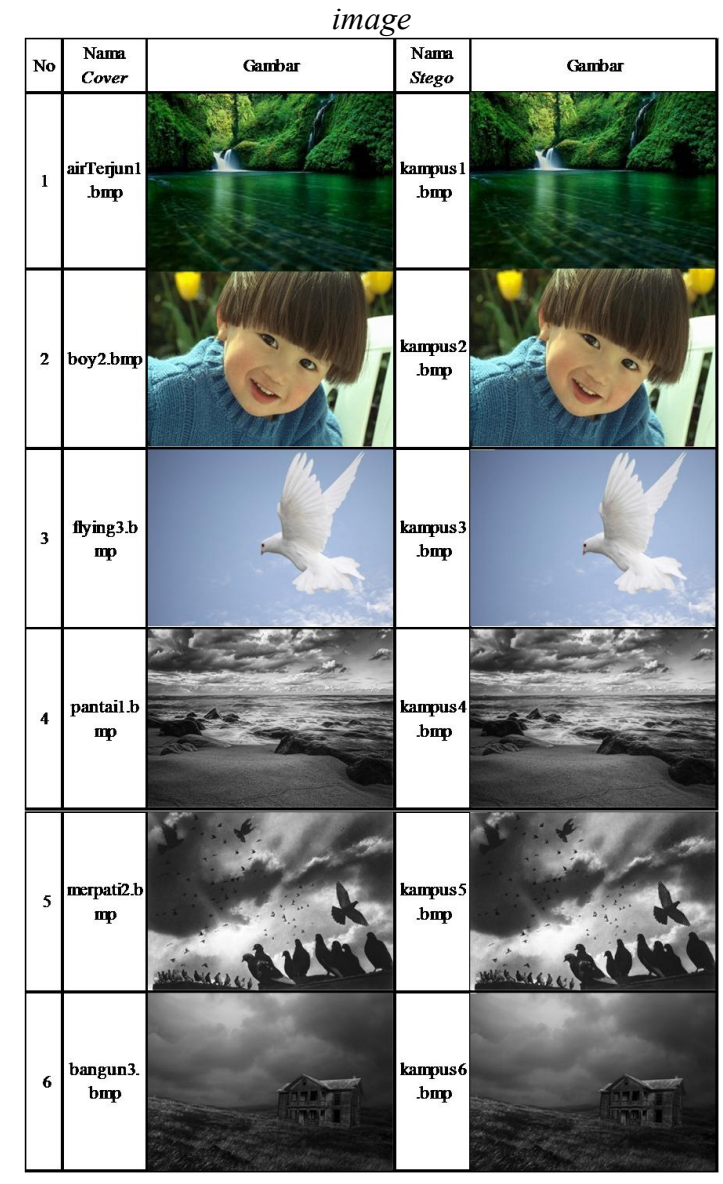

Setelah melakukan proses enkripsi, selanjutnya pada proses dekripsi dihasilkan data sebagai berikut:

Tabel 5.5 Dekripsi Ciphertext

\begin{tabular}{|c|c|c|c|}
\hline & Ciphertext & Kunci & Plaintext \\
\hline 1 & 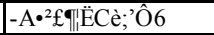 & Fajar Dewandaru! & TI POLTEK MALANG \\
\hline 2 & tó]ç̧⿳⺈冂大 $\div$ CO)DôO & prodi informatik & Fajar Dewandarua \\
\hline 3 & 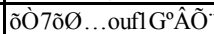 & angkatan ti 2011 & TI Polinema bisa \\
\hline
\end{tabular}

Hasil dekripsi dari ciphertext menghasilkan teks awal yang dimasukkan (plaintext) pada saat proses enkripsi. Dari data tersebut berikut data lengkap saat melakukan proses dekripsi di dalam Tabel 5.6. 
Tabel 5.6 Hasil Proses Dekripsi dan Ekstraksi atau

\begin{tabular}{|c|c|c|c|c|c|c|}
\hline No & $\begin{array}{c}\text { Stego- } \\
\text { image }\end{array}$ & $\begin{array}{c}\text { Ukuran } \\
\text { Stego }\end{array}$ & Dimensi & $\begin{array}{c}\text { File } \\
\text { Plaintext }\end{array}$ & $\begin{array}{c}\text { Ukuran } \\
\text { Plaintext }\end{array}$ & Waktu Proses \\
\hline 1 & $\begin{array}{c}\text { kampus1 } \\
\text { bmp }\end{array}$ & $\begin{array}{c}1351.254 \\
\text { Bytes }\end{array}$ & $750 \times 600$ & kampus1.txt & 18 Bytes & $0: 0: 21: 249$ \\
\hline 2 & $\begin{array}{c}\text { nama1.b } \\
\text { mp }\end{array}$ & $\begin{array}{c}1351.254 \\
\text { Bytes }\end{array}$ & $750 \times 600$ & nama1.txt & 18 Bytes & $0: 0: 21: 571$ \\
\hline 3 & $\begin{array}{c}\text { ujiPlain1. } \\
\text { bmp }\end{array}$ & $\begin{array}{c}1351.254 \\
\text { Bytes }\end{array}$ & $750 \times 600$ & ujiPlain1.txt & 18 Bytes & $0: 0: 21: 239$ \\
\hline 4 & $\begin{array}{c}\text { kampus2 } \\
\text { bmp }\end{array}$ & $\begin{array}{c}810.294 \\
\text { Bytes }\end{array}$ & $640 \times 422$ & kampus2.txt & 18 Bytes & $0: 0: 20: 405$ \\
\hline 5 & $\begin{array}{c}\text { nama2.b } \\
\text { mp }\end{array}$ & $\begin{array}{c}810.294 \\
\text { Bytes }\end{array}$ & $640 \times 422$ & nama2.txt & 18 Bytes & $0: 0: 20: 647$ \\
\hline 6 & $\begin{array}{c}\text { ujiPlain2. } \\
\text { bmp }\end{array}$ & $\begin{array}{c}810.294 \\
\text { Bytes }\end{array}$ & $640 \times 422$ & ujiPlain2.txt & 18 Bytes & $0: 0: 20: 393$ \\
\hline 7 & $\begin{array}{c}\text { kampus3 } \\
\text { bmp }\end{array}$ & $\begin{array}{c}439.542 \\
\text { Bytes }\end{array}$ & $448 \times 327$ & kampus3.txt & 18 Bytes & $0: 0: 19: 908$ \\
\hline 8 & $\begin{array}{c}\text { nama3.b } \\
\text { mp }\end{array}$ & $\begin{array}{c}439.542 \\
\text { Bytes }\end{array}$ & $448 \times 327$ & nama3.txt & 18 Bytes & $0: 0: 20: 078$ \\
\hline 9 & $\begin{array}{c}\text { ujiPlain3. } \\
\text { bmp }\end{array}$ & $\begin{array}{c}439.542 \\
\text { Bytes }\end{array}$ & $448 \times 327$ & ujiPlain3.txt & 18 Bytes & $0: 0: 19: 676$ \\
\hline 10 & $\begin{array}{c}\text { kampus4 } \\
\text { bmp }\end{array}$ & $\begin{array}{c}1200.054 \\
\text { Bytes }\end{array}$ & $800 \times 500$ & kampus4.txt & 18 Bytes & $0: 0: 21: 070$ \\
\hline 11 & $\begin{array}{c}\text { nama4.b } \\
\text { mp }\end{array}$ & $\begin{array}{c}1200.054 \\
\text { Bytes }\end{array}$ & $800 \times 500$ & nama4.txt & 18 Bytes & $0: 0: 21: 337$ \\
\hline 12 & $\begin{array}{c}\text { ujiPlain4. } \\
\text { bmp }\end{array}$ & $\begin{array}{c}1200.054 \\
\text { Bytes }\end{array}$ & $800 \times 500$ & ujiPlain4.txt & 18 Bytes & $0: 0: 21: 104$ \\
\hline 13 & $\begin{array}{c}\text { kampus5 } \\
\text { bmp }\end{array}$ & $\begin{array}{c}833.334 \\
\text { Bytes }\end{array}$ & $640 \times 434$ & kampus5.txt & 18 Bytes & $0: 0: 20: 612$ \\
\hline 14 & $\begin{array}{c}\text { nama5.b } \\
\text { mp }\end{array}$ & $\begin{array}{c}833.334 \\
\text { Bytes }\end{array}$ & $640 \times 434$ & nama5.txt & 18 Bytes & $0: 0: 20: 762$ \\
\hline 15 & $\begin{array}{c}\text { ujiPlain5. } \\
\text { bmp }\end{array}$ & $\begin{array}{c}833.334 \\
\text { Bytes }\end{array}$ & $640 \times 434$ & ujiPlain5.txt & 18 Bytes & $0: 0: 20: 435$ \\
\hline 16 & $\begin{array}{c}\text { kampus6 } 6 \\
\text { bytes }\end{array}$ & $\begin{array}{c}451.638 \\
\text { bymp }\end{array}$ & $448 \times 336$ & kampus6.txt & 18 Bytes & $0: 0: 19: 790$ \\
\hline
\end{tabular}

\section{Kesimpulan}

Langkah pengamanan data pada aplikasi ini adalah data atau pesan teks terlebih dahulu dienkripsi menggunakan metode MMB yang selanjutnya disisipkan pada gambar menggunakan metode LSB. Besar ukuran file gambar sebelum dan setelah proses enkripsi tidak mengalami perubahan serta dapat menyembunyikan file teks ke dalam gambar tanpa diketahui oleh mata manusia secara kasat mata. Dengan kata lain perbandingan dari gambar sebelum dan sesudah proses hampir tidak ada perubahan atau perbedaan.

Besar file hasil dari proses dekripsi (plaintext) sebesar 18 bytes. Besar file tersebut didapat dari panjang plaintext sebesar 16 bytes dan penambahan 2 bytes atau 16 bit dari proses menggunakan metode MMB. Tingkat keberhasilan program $86 \%$ dan tingkat kegagalan program 14\%.

Waktu proses yang dibutuhkan sesuai dengan dimensi gambar yang digunakan, semakin besar gambar tampungan (cover-image) semakin lama juga waktu yang dibutuhkan dalam proses enkripsi dan penyisipan atau encode maupun proses dekripsi dan ekstraksi atau decode.

\section{Saran}

Untuk penelitian selanjutnya data atau pesan yang diamankan dikembangkan menggunakan panjang teks lebih dari 16 karakter.

Untuk lebih meningkatkan keamanan disarankan mengkombinasikan metode MMB dengan teknik steganografi lainnya seperti Discrete Consine Transformation (DCT), Wavelet Transformation, Redundant Pattern Encoding, dan lain-lain..

\section{Daftar Pustaka:}

Adira, 2010, Analisis dan Perancangan Aplikasi Steganografi pada Citra Digital Menggunakan Metode Least Significant Bit (LSB), UIN.

Afiadi, S. 2013. Kriptografi Menggunakan Metoda MMB (Modular Multiplication-Based Block Cipher). Jurusan Teknik Informatika, Universitas Muhammadiyah Jember: Laporan akhir Tidak dipublikasikan.

Anadra, Rezky, 2008, Steganografi Pesan Pada Citra Menggunakan Metode LSB, Bogor: Fakultas Ilmu Komputer Institut Pertanian Bogor.

Busran, 2012, Analisa Komputasi Enkripsi Dan Dekripsi Data Gambar, Teks Dan Audio Dengan Menggunakan Algoritma RC4, 5(1), 32-45

Cahyadi, Tri, 2012, Implementasi Steganografi LSB Dengan Enkripsi Vigenere Cipher Pada Citra JPEG, Transient, 1(4), 282-290

Dahria, Muhammad, 2012, Perangkat Lunak Pembelajaran Kriptografi Metode WAKE (Word Auto Key Encryption), Jurnal SAINTIKOM, 11(3), 143-162

Hidayat, Wildan, 2010, Perlindungan Pesan Rahasia Pada Citra Digital Menggunakan Metode Least Significant Bit Steganografi, Medan: Departemen Matematika, Fakultas Matematika dan Ilmu Pengetahuan Alam Universitas Sumatera Utara.

J, Vandewalee, et all, 1993, Block Ciphers Based on Modular Arithmetic (PDF).

K. Jia, et all, 2010. Practical Time Attack on the Full MMB Block Cipher (PDF)

Kromodimoeljo, Sentot, 2009, Teori dan Aplikasi Kriptografi, Bandung:SPK IT Consulting.

Latief, Mukhlisulfatih, 2010, Studi Perbadingan Enkripsi Menggunakan Algoritma IDEA dan $M M B$, Media Elektrik, 5(2),3-10

Munir Rinaldi, 2003, Kriptografi, Diktat Kuliah IF5054 Kriptografi Program Studi Teknik Informatika, Institut Teknologi Bandung.

Prastyo, Fahri Perdana, 2010, Steganografi menggunakan metode LSB dengan software Matlab, Jakarta:UIN.

Rakhmat, Basuki, 2010, Steganografi Menggunakan Metode Least Significant Bit Dengan Kombinasi Algoritma Kriptografi Vigenère Dan RC4, Jurnal Dinamika Informatika, 5(2),1-17

Suranta, Ricardo Pramana, 2012, Perbandingan Ketahanan Algoritma LSB dan F5 dalam Steganografi Citra, Bandung:ITB 